\title{
Evaluation of Specific Spinal Segmental Stabilizing Exercises in the Treatment of Antenatal Low Back Pain
}

\author{
Fayiz El-Shamy \\ Department of Physical Therapy for Women's Health, Faculty of Physical Therapy, Kafelsheikh University, Kafelsheikh, Egypt
}

\section{Email address:}

ff_elshamy@yahoo.com

\section{To cite this article:}

Fayiz El-Shamy. Evaluation of Specific Spinal Segmental Stabilizing Exercises in the Treatment of Antenatal Low Back Pain. Journal of Gynecology and Obstetrics. Vol. 3, No. 1, 2015, pp. 13-17. doi: 10.11648/j.jgo.20150301.13

\begin{abstract}
Aims: To investigate the effect of specific lumbar stabilizing exercises on relieving antenatal low back pain. Study design: A randomized clinical controlled trial. Place and Duration of study: Department of Obstetrics (antenatal clinic), Kafelsheikh general hospital - Kafelsheikh, between October 2014 and January 2015. Methodology: Twenty pregnant women (age 20-25 years) at 20-24 weeks gestation, clinically diagnosed with low back pain and divided into 2 equal groups (A\&B). Patients in group A were treated by lumbar stabilizing exercises for 12 weeks, patients in group B without any treatment. Low back pain intensity and spine flexibility were measured by mean of a 100-mm horizontal visual analogue scale and side bending test before and after the treatment program. Results: Patients in group A showed significant decrease in low back pain intensity $(\mathrm{P}=0.01)$ and spine flexibility $(\mathrm{P}=0.01)$, while in group $\mathrm{B}$ there were significant increase in low back pain intensity $(\mathrm{P}=0.01)$ without difference in spine flexibility (Right and Left sides) $(\mathrm{P}=0.83$ and 0.6$)$ at the end of the study. There were no significant differences in low back pain intensity $(\mathrm{P}=0.82)$ and spine flexibility (Right and Left sides) $(\mathrm{P}=0.76$ and 0.69$)$ at the beginning of the study. But there were highly significant differences in low back pain intensity $(\mathrm{P}=0.001)$ and spine flexibility (Right and Left sides $)(\mathrm{P}=0.01)$ at the end of the study between both groups, Conclusion: lumbar stabilizing exercises decrease the pain intensity and increase the lumbar range of motion.
\end{abstract}

Keywords: Pregnancy, Low Back Pain, Lumbar Region, Stabilizing Exercises, Lumbar Range of Motion

\section{Introduction}

Low back pain (LBP) is one of the most commonly reported complaints among pregnant women, varying from 50\% to $70 \%$ based on previous studies [1]. Reasons for this include varying definitions and study methodologies [2]. Pregnancy-related low back pain often begins before the end of the first trimester and tends to increase as the pregnancy advances [3]. Although it usually resolves 1-3 months after delivery [4], it may persist in $10 \%-16 \%$ of women $[5,6]$. Pregnancy-related low back pain occurs between the twelfth rib and the gluteal fold [2]. In about $30 \%$ of women, this pain adversely impacts life quality, requiring frequent periods of bed rest, and leading to work absences [7]. The etiology and pathogenesis of back pain related to pregnancy is unclear. Most hypotheses have been focused on hormonal, mechanical, and circulation changes, or a combination of the three [2].Hormonal changes cause a laxity within the joints and ligaments in the back and pelvis [8].Mean while, postural alterations in balance occur from an increase in uterine volume [9]. Also significant to LBP are the effects of fetus weight on the lumbo-sacral nerve roots and the reduction in the blood flow due to compression of the great vessels by the gravid uterus [1]. Ho et al. [10,11]summarized previous studies and advised on current low back pain relief strategies including brief rest, low-heeled shoes, avoiding certain physical activities, heat application, pain medication, exercises(core muscle strength, water gymnastics, yoga), education and ergonomic advice, acupuncture, massage, relaxation, and chiropractise treatment. Amongst these preventive and therapeutic interventions, exercises may be the most beneficial both to the mother as well as the fetus. Regarding maternal health, benefits include the prevention and treatment of gestational diabetes, the prevention of pre-eclampsia, a decrease in excessive weight gain, a decrease in common physical discomforts associated with pregnancy such as backaches, constipation, bloating, and fatigue [12]. In addition, exercise during pregnancy has psychological 
benefits, such as improved self-esteem, mental stability, and decreases in depression symptoms [12]. Exercise is becoming increasingly popular during pregnancy. One goal of exercise during pregnancy is to restore optimal biomechanics [13]. Lumbo pelvic stabilization may be achieved by exercise aiming at appropriate posture and enhanced muscle function. No study has shown significant effects of exercise on back pain during pregnancy. The purpose of the present study was to evaluate the effectiveness of specific spinal segmental stabilizing exercises in preventing or reducing low back pain during pregnancy.

\section{Materials and Methods}

Study design and sampling following the hospitals ethical committee approved the study at obstetric department (Antenatal Clinic) of Kafelsheikh general hospital and written informed consent was obtained from each subject (20 pregnant women). The inclusion criteria were maternal age between 20 and 25 years, primigravid, gestational age between 20 and 24 weeks, housewives, high school graduated, body mass index (BMI) would not exceed $30 \mathrm{~kg} / \mathrm{m} 2$, low back pain experienced anywhere from T12 to the gluteal fold with or without radiation to the knee that started during the current pregnancy, and any degree of pain. The main exclusion criterion was the presence of low back and/ or pelvic pain before pregnancy. Also excluded were subjects with pain radiating to below the knee, chronic back pain for more than 3 months, known congenital anomalies of the spine, known rheumatic disease affecting the locomotion system or previous surgery of the lumbar spine or pelvis. and any uncontrolled medical or obstetric condition for which aerobic exercise would be contraindicated according to American College of Obstetricians and Gynecologists (ACOG) Committee guidelines for exercise during pregnancy [13]. Every woman who missed three sessions was excluded from the study. The design of this study was a clinical controlled trial. This study was done from October 2014 to January 2015.Before intervention, severity of pain was measured by mean of a 100-mm horizontal visual analogue scale(VAS) for the worst pain with a range from 0 to $100 \mathrm{~mm}$, where 0 denoted no pain and 100 worst possible pain [14]. Flexibility of spine on the left and the right side was measured by Side Bending Test. The same re evaluation was performed after 12-weeks for both groups (A\&B). Assuming a 30\% decrease in back pain in the study group, with an $\alpha$ value of $95 \%$ and a $\beta$ value of $80 \%$, it was calculated that 40 participants in each group would be needed to achieve significance. The training program focused on transversus abdominis, the lumbar multifidus, and pelvic floor muscles. The exercise programs were included 11 exercises in $50 \mathrm{~min}$. These exercises were: $5 \mathrm{~min}$ of slow walking, and $10 \mathrm{~min}$ of general warming up, $10 \mathrm{~min}$ of anaerobic exercise, $20 \mathrm{~min}$ of specific spinal segmental stabilizing exercises and $5 \mathrm{~min}$ as cooling down and return to the first position. The intensity of the exercise was controlled by maternal pulse rate. For pulse rates exceeding 140 per minute, the exercise stopped and the participant was excluded from the study. It performed by physiotherapist specialized in women health at antenatal classes, The number of participants in each class ranged from 3 to 5.The participants were randomly assigned to one of the two groups; study group (A) and a control group (B). through a block-style randomization scheme [15].Women in group(A) were performed the exercise programs three times a week for 12 weeks, In addition to verbal information on basic back care and posture during pregnancy. Women in the study group were also given a handout illustrating and explaining the exercise program. Women in group (B) were not given specific instructions regarding whether they should perform any exercise. all participants in both groups(A\&B) were given an information pamphlet which included advices on correct posture while sitting and standing, lifting and carrying heavy objects, use of support pillows (especially while sleeping), and methods to turn around in bed or to get up from bed without exerting excessive strain on the lower back.

Statistical analysis involved the calculation of the means and standard deviations for each of the variables measured. Paired t-tests were used to evaluate within-group changes. Differences between the two groups were assessed using an independent samples t-test. A P-value of $<0.05$ was taken to represent statistical significance. Data analysis was performed using SPSS software version 16.

\section{Results}

All data had been collected and statistically analyzed and presented under the following headings;

\subsection{General Characteristics of the Patients}

In this study, 20 participants were divided randomly into two equal groups (A\&B). Group (A): 10 participants were included in this group; the mean age and BMI were $(22.04 \pm 1.2)$ years and $(27.8 \pm 2.1) \mathrm{Kg} / \mathrm{m}^{2}$. Group (B): 10 participants were included in this group; the mean age and BMI were (21.9 \pm 1.8$)$ years and $(26.9 \pm 2.8) \mathrm{Kg} / \mathrm{m}^{2}$.There was no significant difference $(\mathrm{P}=0.83$ and 0.69$)$ between both groups $(\mathrm{A} \& \mathrm{~B})$ regarding their ages and $\mathrm{BMI}$ respectively.

\subsection{Low Back Pain (LBP) Intensity on Visual Analogue Scale (mm)}

Group A: There was statistically significant decrease in participant's LBP intensity $(\mathrm{P}=0.01)$, as the mean value of pain intensity was $63.9 \pm 8.2$ at the beginning of the study, while it was $50.7 \pm 10.1$ at the end of the study (Table 1).

Group B: There was statistically significant increase in participant's LBP intensity $(\mathrm{P}=0.01)$, as the mean value of pain intensity was $62.1 \pm 6.8$ at the beginning of the study, while it was $68.3 \pm 5.4$ at the end of the study (Table 1).

Between both groups (A\&B), there was no statistically significant difference in participant's LBP intensity $(\mathrm{P}=0.82)$ at the beginning of the study. But there was highly significant increase $(\mathrm{P}=0.001)$ at the end of the study (Table 2$)$. 
Table (1). Mean values of Low Back Pain intensity for participants in both groups $(A \& B)$ at pre and post treatment.

\begin{tabular}{lllll}
\hline & \multicolumn{3}{l}{ LBP intensity $(\mathbf{m m})$} \\
\cline { 2 - 5 } & \multicolumn{2}{l}{ Group A } & \multicolumn{2}{l}{ Group B } \\
\cline { 2 - 5 } & Pre & Post & Pre & Post \\
\hline Mean & 63.9 & 50.7 & 62.1 & 68.3 \\
\pm SD & \pm 8.2 & \pm 10.1 & \pm 6.8 & \pm 5.4 \\
P. value & 0.01 & & 0.01 & \\
Significance & $\mathrm{S}$ & & $\mathrm{S}$ & \\
\hline
\end{tabular}

SD: Standard Deviation, P. value: Probability value, S: Significant.

Table (2). Comparison between the mean values of Low Back Pain intensity for participants in both groups $(A \& B)$ at pre and post treatment.

\begin{tabular}{lllll}
\hline & \multicolumn{3}{l}{ LBP intensity $(\mathbf{m m})$} & \\
\cline { 2 - 5 } & \multicolumn{2}{l}{ Pre-treatment } & \multicolumn{2}{l}{ Post-treatment } \\
\cline { 2 - 5 } & Group A & Group B & Group A & Group B \\
\hline Mean & 63.9 & 62.1 & 50.7 & 68.3 \\
\pm SD & \pm 8.2 & \pm 6.8 & \pm 10.1 & \pm 5.4 \\
P. value & 0.82 & & 0.001 & \\
Significance & NS & & HS & \\
\hline
\end{tabular}

SD: Standard Deviation, P. value: Probability value, S: Significant, NS: Non significant, HS: Highly significant.

\subsection{Spine Flexibility (cm)}

\subsubsection{Right Side}

Group A: There was statistically significant decrease in participant's spine flexibility $(\mathrm{P}=0.01)$, as the mean value of the spine flexibility was $20.19 \pm 2.37$ at the beginning of the study, while it was $14.8 \pm 1.01$ at the end of the study(Table 3 ).

Group B: There was no significant difference in participant's spine flexibility $(\mathrm{P}=0.83)$, as the mean value of the spine flexibility was $20.8 \pm 2.5$ at the beginning of the study, while it was $20.91 \pm 3.2$ at the end of the study(Table 3). Between both groups (A\&B), there was no significant difference in participant's spine flexibility $(\mathrm{P}=0.76)$ at the beginning of the study. But there was significant difference $(\mathrm{P}=0.01)$ at the end of the study (Table 4$)$.

\subsubsection{Left Side}

Group A: There was statistically significant decrease in participant's spine flexibility $(\mathrm{P}=0.01)$, as the mean value of the spine flexibility was $20.3 \pm 2.29$ at the beginning of the study, while it was $15.01 \pm 1.9$ at the end of the study (Table 3). Group B: There was no significant difference in participant's spine flexibility $(\mathrm{P}=0.6)$, as the mean value of the spine flexibility was $20.74 \pm 2.5$ at the beginning of the study, while it was $21.7 \pm 2.6$ at the end of the study (Table 3 ).

Between both groups (A\&B), there was no significant difference in participant's spine flexibility $(\mathrm{P}=0.69)$ at the beginning of the study. But there was significant difference $(\mathrm{P}=0.01)$ at the end of the study (Table 4$)$.
Table (3). Mean values of Spine flexibility for participants in both groups $(A \& B)$ at pre and post treatment.

\begin{tabular}{|c|c|c|c|c|}
\hline & \multicolumn{4}{|c|}{ Spine Flexibility(cm) } \\
\hline & \multicolumn{2}{|c|}{ Group A } & \multicolumn{2}{|c|}{ Group B } \\
\hline & Pre & Post & Pre & Post \\
\hline Right side Mean & 20.19 & 14.8 & 20.8 & 20.91 \\
\hline$\pm \mathrm{SD}$ & \pm 2.37 & \pm 1.01 & \pm 2.5 & \pm 3.2 \\
\hline p. value & 0.01 & & 0.83 & \\
\hline Significance & $\mathrm{S}$ & & N S & \\
\hline \multicolumn{5}{|l|}{ Left side } \\
\hline Mean & 20.3 & 15.01 & 20.74 & 21.7 \\
\hline$\pm \mathrm{SD}$ & \pm 2.29 & \pm 1.9 & \pm 2.5 & \pm 2.6 \\
\hline p. value & 0.01 & & & \\
\hline Significance & $\mathrm{S}$ & & & \\
\hline
\end{tabular}

SD: Standard Deviation, P. value: probability value, NS: Non Significant, S: Significant.

Table (4). Comparison between the mean values of Spine Flexibility for participants in both groups $(A \& B)$ at pre and post treatment.

\begin{tabular}{lllll}
\hline & \multicolumn{3}{l}{ Spine Flexibility(cm) } \\
\cline { 2 - 5 } & \multicolumn{2}{l}{ Pre-treatment } & \multicolumn{2}{l}{ Post-treatment } \\
\cline { 2 - 5 } & Group A & Group B & Group A & Group B \\
\hline Right side Mean & 20.19 & 20.8 & 14.8 & 21.91 \\
\pm SD & \pm 2.37 & \pm 2.5 & \pm 1.01 & \pm 3.2 \\
p. value & 0.76 & & 0.01 & \\
Significance & NS & & S & \\
Left side & & & \multicolumn{2}{c}{15.01} \\
Mean & 20.3 & 20.74 & 21.7 & \pm 2.5 \\
\pm SD & \pm 2.29 & \pm 1.9 & \pm 2.6 & \multicolumn{2}{c}{0.01} \\
p. value & 0.69 & & \multicolumn{2}{c}{ S } \\
Significance & NS & & \multicolumn{2}{c}{} \\
\hline
\end{tabular}

SD: Standard Deviation, P. value: probability value, NS: Non Significant, S: Significant.

\section{Discussion}

This study shows the effect of specific spinal segmental stabilizing exercise on pregnant women's low back pain. No difference was showed in pain intensity and spine flexibility between the women in the two groups at the beginning of the study. After ending the exercise programs, women in the exercise group showed lower intensity of low back pain with improvement of spine flexibility in comparison to the beginning of study. In the control group, intensity of low back pain increased without improvement of spine flexibility as pregnancy advanced. The results were supported by Taimela et al.,[16] who reported that there were a significant decrease in low back pain severity, physical impairment and long term absence from work after the rehabilitation program which included lumbar stabilization exercises to strength multifidus muscle. Treatment programs comprising stabilizing exercises significantly decrease pain intensity and increase the quality of life of women with pregnancy-related low back pain, both during pregnancy [17] and postpartum [18]. These exercises strengthen the paraspinal and abdominal muscles controlling lumbopelvic stability. Contraction of the transversus abdominis muscle leads to stabilization of the lumbar spine and significantly reduces laxity of the sacroiliac joints, thereby facilitating the rehabilitation of non-pregnant patients experiencing low back pain [19]. The specific stabilizing 
exercises of the present study were tailored toward strengthening the transversus abdominis, which is considered a primary stabilizer of the lumbo pelvic area $[18,19]$. Pelvic floor exercises were included because they work together with the transversus abdominis to stabilize the pelvis [20]. Exercise during pregnancy has psychological benefits, such as improved self-esteem, mental stability, and decreases in depression symptoms [21]. According to the centre of gravity theory, which posits that during pregnancy the centre of gravity moves forward and thus requiring strong core muscles to maintain the stability of lumbar spine and the pelvic girdle[22]. Previous studies have shown that strengthening the body's core muscles during pregnancy reduces the chance of back injury[23] and diminishes back pain Because these muscle groups stabilize the trunk, core strength enhances the body's balance[24]..The obtained results disagree with Hides et al .,[25] who reported no change in lateral bending to the right and to the left in the stabilizing group who used modified - modified schober test. The findings of the present study may be limited by cultural and ethical issues, the small sample size, this small sample size does not assure that group differences are indeed irrelevant, Although randomized, blinding was not possible; however, the study demonstrated that it is possible to help women with low back pain during pregnancy, despite the difficulties in implementing an exercise program. This study did not attempted to measure 'instability' prior to the stabilization exercises, and whether the exercises had been sufficiently specific to improve this 'abnormality'. Thus, it is not known if a necessary condition for a better outcome is an improvement in this parameter. This would be an important area for future research. Lack of an objective outcome measure such as measuring pain intensity by VAS is another limitation of the present study. Lastly, since the study was conducted in a regional hospital in Kafrelsheikh governorate with primigravida women, caution should be taken in generalizing findings to other setting and multiparaous women.

\section{Conclusion}

In summary, this study suggests that the clinical application of lumbar stabilizing exercises programme could been effective adjunctive tool for second and third trimester women in reducing low back pain, and diminishing daily life interference.

\section{Acknowledgements}

The author wish to express their greatest appreciation to the women who agreed to participate in this study. The assistance of physicians and the nursing staff of the hospital in recruiting women is also gratefully acknowledged.

\section{References}

[1] Vermani, E., Mittal, R. and Weeks, A. "Pelvic girdle pain and low back pain in pregnancy: a review".Pain Practice.10, 60-71, 2010 .
[2] Vleeming, A., Albert, H., Östgaard, HC., Sturreson, B., Stuge, B. "European guidelines for the diagnosis and treatment of pelvic girdle pain". Eur Spine J. 17,794-819, 2008.

[3] Östgaard, HC., Andersson, GBJ., Karlsson, K. "Prevalence of back pain in pregnancy". Spine (Phila Pa 1976). 16(5), 549-52, 1991.

[4] Östgaard, HC., Zetherstrom, G. and Roos-Hansson, E. "Regression of back and posterior pelvic pain after pregnancy". Spine (Phila Pa 1976). 21(23), 2777-80, 1996.

[5] Svensson, HO., Andersson, GB., Hagstad, A. and Jansson, PO. "The relationship of low-back pain to pregnancy and gynecologic factors". Spine (Phila Pa 1976). 15(5), 371-5, 1990.

[6] Östgaard, HC., Zetherström, G. and Roos-Hansson, E. "Back pain in relation to pregnancy: a 6-year follow-up". Spine (Phila Pa 1976). 22(24), 2945-50, 1997.

[7] Mogren,I. Perceived health six months after delivery in women who have experienced low back pain and pelvic pain during pregnancy". Scandinavian Journal of Caring Sciences. 21, 447$455,2007$.

[8] Forrester,M. "Low back pain in pregnancy". Acupuncture in Medicine. 21, 36-41, 2003.

[9] Wang,S.M.,Dezinno,P.,Maranets,I.,Berman,M.R.,CaldwellAn drews,A.A. and Kain, Z.N."Low back pain during pregnancy: prevalence, risk factors, and outcomes". Obstetrics and Gynecology.104, 65-70, 2004.

[10] Ho,S.S.M., Yu,W.W.M., Lao,T.T., Chow, D.H.K., Chung, J.W.Y. and Li,Y." Effectiveness of maternity support belts in reducing low back pain during pregnancy: a review". Journal of Clinical Nursing.18, 1523-1532, 2009a.

[11] Ho,S.S.M., Yu,W.W.M., Lao,T.T., Chow,D.H.K., Chung,J.W.Y. and Li,Y." Garment needs of pregnant women based on content analysis of in-depth interviews". Journal of Clinical Nursing. 18, 2426-2435, 2009b.

[12] American College of Obstetricians and Gynecologists, Exercise During Pregnancy: ACOG Patient Education Pamphlet. ACOG, Washington, DC, 2003.

[13] ACOG Committee, Opinion No. 267. "Exercise during pregnancy and the postpartum period". Obstet Gynecol. 99,171-3, 2002.

[14] Collins, S.L., Moore, R.A. and McQuay, H.J. "The visual analogue pain intensity scale: what is moderate pain in millimeters?". Pain. 72, 95-97, 1997.

[15] Piantadosi, s. "Clinical trial: a methodologic perspective". John wily\& sons, new York, 1997.

[16] Taimela, S., Diederich, C., Hbsch, M. and Heinricy. M.: "The role of physical exercise and inactivity in pain recurrence and absenteeism form work after active outpatient rehabilitation for recurrent or chronic low back pain,, Spine. 25(14), 1809-1816, 2000 .

[17] Garshasbi, A. and Faghih Zadeh, S. "The effect of exercise on the intensity of low back pain in pregnant women". Int J Gynecol Obstet. 88(3),271-5, 2005.

[18] Stuge, B., Lærum, E., Kirkesola, G. and Vøllestad, N. "The efficacy of a treatment program focusing on specific stabilizing exercises for pelvic girdle pain after pregnancy: arandomized controlled trial". Spine (Phila Pa 1976). 29(4), 351-9, 2004. 
[19] Richardson, CA., Snijders, CJ., Hides, JA., Damen, L., Pas, MS and Storm, J. "The relation between the transversus abdominis muscles, sacroiliac joint mechanics, and low back pain". Spine (Phila Pa 1976). 27(4), 399-405, 2002.

[20] Brayshaw, E. "Exercises for pregnancy and childbirth: a practical guide for educators". Second edition. Edinburgh: Books for Midwives. 2003.

[21] Poudevigne, M.S. and O`Connor, P.J."Physical activity and mood during pregnancy. Medicine \&Science in Sports and Exercise.37,1374-1380, 2005.

[22] BorgStein, J. and Dugan,S.A."Musculoskeletal disorders of pregnancy, delivery and postpartum". Physical Medicine and rehabilitation Clinics of North America. 18, 459-476, 2007.
[23] Petrofsky, J.S., Batt,J., Brown, J. and et al." Improving the outcomes after back injury by a core muscle strengthening program". Journal of Applied Research. 8, 62-75, 2008.

[24] Dumas, G.A., Reid,J.G., Wolfe,L.A., Griffin, M.P. and McGrath, M.J." Exercise, posture, and back pain during pregnancy. Part2. Exercise and back pain. Clinical Biomechanics.10,104-109, 1995.

[25] Hides, J., Strokes Saide, M., Jull, G. and Cooper D." Evidence of lumbar multifidus wasting ipsilateral to symptoms with acute/sub acute low back pain". Spine. 19, 165-172, 1994. 